\title{
ANTHROPOS:
}

Jurnal Antropologi Sosial dan Budaya

Available online http://jurnal.unimed.ac.id/2012/index.php/anthropos

\section{Adaptasi Masyarakat Transmigran di Desa Batang Pane II, Kecamatan Padang Bolak, Kabupaten Padang Lawas Utara}

\author{
Yuyun Trisna Yuningsih \& Nurjannah*
}

\author{
Program Studi Pendidikan Antropologi, Fakultas Ilmu Sosial \\ Universitas Negeri Medan, Indonesia
}

Diterima: Januari 2019; Disetujui: Januari 2019; Diterbitkan: Januari 2019

\begin{abstract}
Abstrak
Penelitian ini bertujuan untuk mengetahui sejarah, faktor pendorong, adaptasi, solidaritas sosial, dan hambatan yang dihadapi masyarakat transmigran etnik Jawa dan Sunda dalam beradaptasi di Desa Batang Pane II, Kecamatan Padang Bolak, Kabupaten Padang Lawas Utara. Penelitian ini menggunakan penelitian deskriptif kualitatif dengan subjek masyarakat transmigran etnis Jawa, Sunda, dan juga penduduk asli yaitu masyarakat sub suku Batak Angkola. Hasil penelitian menunjukan bahwa sejarah transmigrasi mereka merupakan hasil dari program transmigrasi umum tahun 1982 pada masa pemerintahan presiden Soeharto. Faktor pendorongnya adalah karena ingin meningkatkan taraf hidup, dan mendapat hidup yang lebih sejahtera. Adaptasi masyarakat transmigran berjalan dengan baik, dibuktikan dengan adanya interaksi dan komunikasi yang berlangsung antara masing-masing etnik. Solidaritas sosial yang terjadi, terlihat pada berbagai macam kegiatan yang dilakukan secara bersama-sama, saling bekerjasama dan terjalin kekompakan dalam bermasyarakat. Hambatan dalam adaptasi dengan lingkungan tanah yang tandus sehingga masyarakat tidak bisa bercocok tanam selain tanaman keras pada awal mula bertransmigrasi. Hambatan dalam berkomunkasi itu dikarenakan masing-masing etnik mempunyai bahasa yang berbeda. Kesimpulan yang didapat bahwa masyarakat transmigran dengan penduduk asli masing-masing saling beradaptasi. Proses adaptasi tidak sepenuhnya terjadi secara alamiah, namun telah diprogramkan oleh pemerintah dengan bukti peletakan rumah untuk warga transmigran dan penduduk asli dilakukan secara acak.
\end{abstract}

Kata Kunci: Adaptasi, Faktor Pendorong, Solidaritas Sosial, Hambatan, Masyarakat Transmigran

\begin{abstract}
This study aims to determine the history, driving factors, adaptation, social solidarity, and barriers faced by Javanese and Sundanese ethnic transmigrant communities in adapting in Batang Pane II Village, Padang Bolak District, North Padang Lawas Regency. This study used a qualitative descriptive study with the subject of Javanese, Sundanese, and indigenous ethnic transmigrant communities namely the Batak Angkola sub-community. The results of the study show that the history of their transmigration was a result of the general transmigration program of 1982 under the rule of President Suharto. The driving factor is because you want to improve your standard of living, and get a more prosperous life. The adaptation of the transmigrant community went well, as evidenced by the interaction and communication that took place between each ethnic group. The social solidarity that occurs, can be seen in various kinds of activities carried out jointly, collaborating with each other and establishing cohesiveness in the community. Barriers to adaptation to barren soil environments so that people cannot grow crops other than perennials at the beginning of transmigration. The obstacle in communicating is because each ethnic group has a different language. The conclusion is that transmigrant communities with indigenous people each adapt to each other. The adaptation process does not fully occur naturally, but has been programmed by the government with evidence of laying houses for transmigrants and indigenous people randomly.

Keywords: Adaptation, Driving Factors, Social Solidarity, Obstacles, Transmigrant Society
\end{abstract}

How to Cite: Yuningsih, Y.T. \& Nurjannah (2019). Adaptasi Masyarakat Transmigran di Desa Batang Pane II, Kecamatan Padang Bolak, Kabupaten Padang Lawas Utara. Anthropos: Jurnal Antropologi Sosial dan Budaya, 4 (2): 188-193.

*Corresponding author: ISSN 2460-4585 (Print)

E-mail: nurjannah@unimed.ac.id. ISSN 2460-4593 (Online) 


\section{PENDAHULUAN}

Setiap manusia selalu berkeinginan untuk terpenuhinya kebutuhan hidup baik itu pangan, sandang dan papan yang layak. Namun dengan persaingan yang ketat di kota-kota besar yang padat penduduk seperti Pulau Jawa, memungkinkan orang-orang yang tidak berpendidikan tinggi dan kurang memiliki keterampilan di pulau tersebut akan tersisihkan. Hal ini lah yang menyebabkan banyaknya masyarakat yang masih hidup di bawah garis kemiskinan di kota-kota padat penduduk.

Sehubungan dengan hal tersebut, maka program transmigrasi dianggap penting dalam rangka memecahkan masalah kepadatan penduduk dan juga kemiskinan khususnya di Pulau Jawa. Mereka yang mengikuti transmigrasi pada umumnya adalah dari kelompok masyarakat yang berpendapatan rendah, tidak mempunyai lahan yang cukup untuk mengembangkan usaha- usaha pertanian.

Berdasarkan hal itu maka sudah sewajarnya mereka ini mendambakan adanya tingkat kesejahteraan yang lebih baik dibandingkan kehidupannya di daerah asal. Seperti tujuan transmigrasi tersebut diadakan yaitu salah satunya untuk meningkatkan taraf hidup masyarakat di tengah-tengah persaingan hidup yang keras di perkotaan serta untuk memecahkan masalah kepadatan penduduk yang dampaknya akan mengkhawatirka daerah itu sendiri. Untuk itu mereka bersedia mengadu nasib di pulau-pulau lain di luar pulau Jawa dan meninggalkan kota kelahirannya demi sebuah harapan kehidupan yang sejahtera.

Pada zaman pemerintahan Soeharto, telah diadakan transmigrasi umum ke daerah-daerah luar Jawa yang salah satunya yaitu Sumatera Utara. Sumatera Utara dijadikan salah satu tujuan transmigrasi dikarenakan pada saat itu tingkat kepadatan penduduk di Sumatera Utara masih dianggap rendah. Untuk itu, Pemerintah memutuskan untuk menempatkan masyarakat transmigran di Sumatera Utara.

Penempatan yang dilakukan tentunya melibatkan dua Pemerintah Derah yakni Daerah Tujuan yang akan menyediakan ruang sekaligus tempat tinggal, tempat berusaha dan bekerja, serta Pemerintah Daerah Asal yang akan menyediakan sumber daya manusia sesuai dengan kebutuhan daerah tujuan. Selanjutnya masyarakat transmigran ditempatkan di Kecamtan/Kabupaten yang telah disepakati oleh Pemerintah Daerah Asal dan Pemerintah Daerah Tujuan.

Batang Pane II merupakan salah satu desa yang berada di wilayah Kecamatan Padang Bolak, Kabupaten Padang Lawas Utara, Provinsi Sumatera Utara. Ibu kota kecamatan ini berada di Gunung Tua. Berdasarkan data sejarah, Desa Batang Pane II yang hanya dihuni oleh penduduk berasal dari pulau Jawa ini merupakan Desa yang berada di tengah-tengah pemukiman masyarakat Batak Angkola. Mereka datang ke daerah ini melalui program transmigrasi masa orde baru dengan salah satu tujuan untuk meningkatkan kesejahteraan rakyat. Para transmigran ini sejak tahun 1982, ditempatkan pada salah satu tempat yang memang sengaja dibuka sebagai tempat bermukim mereka. Dalam penempatannya, di setiap Desa tidak hanya diperuntukan bagi pendatang yang berasal dari satu daerah asal saja, akan tetapi setiap desa dihuni penduduk dari ketiga daerah asal itu yaitu penduduk suku Jawa dari (Jawa Timur dan Jawa Tengah) dan juga suku Sunda dari (Jawa Barat). Desa inilah yang kemudia dikenal dengan nama "Desa Trans" atau unit Pemukiman Transmigran (UPT) Batang Pane.

Awal kehadiran masyarakat trasnmigran suku Jawa dan Sunda di tengah-tengah pemukiman masyarakat Angkola, tidak mudah bagi mereka untuk bersosialisai dengan masyarakat setempat. Salah satu penyebabnya adalah perbedaan bahasa dari masing-masing etnis (Jawa, Sunda, dan Angkola), sehingga sering terjadi kesalahan dalam berkomunikasi. Untuk itu, serangkaian upaya dilakukan suku Jawa dan Sunda untuk beradaptasi dengan kelompok masyarakat asli (Angkola) dengan tujuan agar keberadaan mereka diterima di dalam hubungan masyarakat.

Bungin (2008) menyatakan "adaptasi itu sendiri diartikan sebagai naluri yang mendorong manusia untuk menyatukan dirinya dengan kelompok yang lebih besar dalam kehidupan manusia lain disekelilingnya bahkan mendorong manusia menyatu dengan alam fisiknya."

Pengertian adaptasi tersebut di atas, di dalam pembauran dengan suku Batak Angkola yang merupakan kelompok yang dominan, suku Jawa dan Sunda sebagai pendatang harus mampu menyatukan dirinya dan melakukan penyesuaian 
diri atau adaptasi di daerah setempat karena mengingat predikat suku Jawa dan Sunda adalah kelompok pendatang. Meskipun telah jelas, pembauran akan menyebabkan bertemunya kebudayaan-kebudayaan yang berbeda, namun masyarakat harus saling menerima perbedaan, bahkan dimungkinkan masyarakat pendatang dapat menerima unsur-unsur kebudayaan setempat ke dalam kebudayaannya sendiri ataupun sebaliknya, melalui cara-cara berinteraksi dalam pergaulan sehari-hari dalam waktu yang lama.

Proses adaptasi masyarakat etnis Jawa, dan Sunda sebagai pendatang dan juga etnis Angkola sebagai penduduk asli harus tetap menjaga hubungan antar etnis agar hubungan terjalin dengan baik. Selain itu, solidaritas juga merupakan hal yang sangat penting, agar masyarakat dapat hidup berdampingan secara damai, saling membantu dalam setiap aktivitas yang dilakukan secara kolektif.

Apabila adaptasi telah berhasil, hubungan antar etnis terjalin harmonis, solidaritas sosial berjalan dengan baik, kemungkinan besar masyarakat akan saling menerima dan hidup secara rukun yang menunjukan proses-proses tersebut mencapai tingkat keberhasilan. Tidak dipungkiri, banyak masyarakat transmigran kembali lagi ke daerah asalnya masing-masing karena ketidakmampuannya untuk beradaptasi dengan lingkungan dan masyarakat di tempat tujuan.

Berbagai kajian dan tulisan telah dilakukan tentang fenomena migrasi dan pola adaptasi. Seperti halnya kajian skripsi Sihar Lubis (2011) mengenai pola interaksi sosial migran di Desa Sirpangbolon, Kecamatan Garoga, Kabupaten Tapanuli Utara. Hasil kajiannya mengungkapkan bahwa Etnis Jawa sebagai kaum pendatang melakukan adaptasi dengan penduduk asli Batak Toba. Interaksi antar etnis berjalan dengan baik, dan tidak pernah ada konflik yang terjadi meski mereka dihadapkan dengan perbedaan-perbedaan baik dari segi budaya, tradisi, dan lain sebagainya. Namun dengan adaptasi tersebut, masyarakat antar etnis dapat membaur seperti kekompakan yang terjadi apabila adanya acara adat, kegiatan gotong royong, dan kegiatan sosial lainnya.

\section{METODE PENELITIAN}

Penelitian ini deskriptif kualitatif penelitian lapangan. Bogda dan Taylor dalam Moleong (2009) mengemukakan, bahwa "metodologi kualitatif sebagai prosedur peneilitan yang menghasilkan data deskriptif berupa katakata tertulis atau lisan dari orang-orang dan perilaku yang dapat diamati."

Penulis melakukan penelitian deskriptif dengan menggunakan pendekatan kualitatif agar peneliti dapat menggambarkan proses adaptasi yang dilakukan masyarakat transmigran di Desa Batang Pane II, Kecamatan Padang Bolak, Kabupaten Padang Lawas Utara kepada pembaca secara sistematis, faktual dan akurat. Penulis juga menggunakan study lapangan atau biasa disebut Field Research.

Sugiyono (2012) mengatakan subjek penelitian yang dimaksud adalah orang (actor) sebagai pelaku dalam kegiatan yang akan diteliti. Dalam penelitian ini, actor sebagai pelaku yang dimaksud adalah masyarakat transmigran (Etnis Jawa dan Sunda) sebagai pendatang pada tahun 1982 dan penduduk asli (suku Angkola) di Desa Batang Pane II, yang dijadikan sebagai narasumber untuk menggali semua informasi yang diperlukan.

Objek penelitian adalah (activity) yaitu kegiatan yang akan diteliti dari si pelaku. Adapun aktivitas yang dimaksud dalam penelitian ini yaitu adaptasi masyarakat transmigran di Desa Batang Pane II, dengan fokus penelitiannya yaitu pada kegiatan adaptasi masyarakat yang menyangkut adaptasi terhadap lingkungan geografis, adaptasi terhadap penduduk asli, interaksi antar etnis, hubungan sosial antar etnis, dan juga solidaritas sosial antar etnis pendatang dengan penduduk asli.

\section{HASIL DAN PEMBAHASAN}

\section{Sejarah Transmigrasi}

Menurut Mulyadi (2006), "transmigrasi adalah suatu sistem pembangunan terpadu yang merangkum seperangkat prinsip dan metode untuk penyelenggaraan pemukiman dan kehidupan baru bagi suatu kelompok masyarakat". Transmigrasi sebagai upaya untuk mencapai keseimbangan penyebaran penduduk, juga dimaksudkan untuk menciptakan perluasan kesempatan kerja, meningkatkan produksi dan meningkatkan pendapatan yang harus dirasakan sebagai kesempatan baru bagi kehidupan baru, yang jauh lebih baik dari daerah tempat asalnya. 
Desa Batang Pane II ini adalah sebuah Desa yang dibentuk atas hasil program transmigrasi yang diadakan tahun 1982 pada masa pemerintahan Soeharto. Desa ini semula bernama Desa Trans, yang artinya dihuni oleh kelompok masyarakat transmigrasi, yang asalnya dari pulau Jawa (Jawa Tengah dan Jawa Barat). Namun kemudian Desa ini diganti dengan nama Desa Batang Pane II, untuk menghilangkan sebutan kelompok masyarakat trans yang seakan-akan terasing dari masyarakat lainnya yang menempati wilayah Padang Bolak.

Batang Pane itu sendiri diambil dari nama pohon, karena sebelum Desa itu dibuka tempat tersebut banyak ditumbuhi pohon-pohon Pane dengan batang yang besar, sehingga nama pohon tersebut dijadikan nama untuk mengganti nama Desa Trans menjadi Desa Batang Pane II yang saat ini dijadikan sebagai pemukiman etnik.

\section{Faktor Pendorong}

Setiap manusia dalam hidupnya pasti menginginkan kehidupan yang layak, bisa memenuhi kebutuhan hidupnya, dan mendapatkan kesejahteraan. Hal tersebutlah yang menjadi motif seseorang untuk ikut bertransmigrasi. Dari alasan tersebut, dapat dikatakan bahwa yang menjadi motif utama adalah karena keadaan ekonomi. Para transmigran sangat berharap bahwa program transmigrasi tersebut akan membawa dampak dan mobilisasi yang lebih baik dalam bidang ekonomi.

\section{Adaptasi}

Bungin (2008) adaptasi adalah "naluri ini yang mendorongnya untuk selalu menyatukan hidupnya dengan orang lain dalam kelompoknya". Naluri berkelompok itu juga yang mendorong manusia untuk menyatukan dirinya dengan kelompok yang lebih besar dalam kehidupan manusia lain disekelilingnya bahkan mendorong manusia menyatu dengan alam fisiknya.

Soekanto (2006) memberikan beberapa batasan pengertian dari adaptasi sosial, yaitu: (1) Proses mengatasi halangan-halangan dari lingkungan, (2) penyesuaian terhadap normanorma untuk menyalurkan ketegangan, (3) proses perubahan untuk menyesuaikan dengan situasi yang berubah, (4) mengubah agar sesuai dengan kondisi yang diciptakan, (5) memanfaatkan sumber-sumber yang terbatas untuk kepentingan lingkungan, dan (6) penyesuaian aspek budaya dan aspek lainnya sebagai hasil seleksi alamiah.

Pengertian adaptasi di atas, dapat disimpulkan bahwa adaptasi adalah kemampuan atau kecendrungan manusia dalam menyesuaikan diri dengan lingkungan baru untuk dapat tetap bertahan hidup dengan baik. Seseorang dalam kehidupan bersama, (sampai tahap-tahap tertentu) harus mengkoordinasikan dan mengintegrasikan perilakunya, untuk menghindarkan terjadinya kekacauan. Untuk itu, dalam proses adaptasinya manusia tidak terlepas dari interaksi antar sesamanya untuk menghadirkan situasi keserasian dan harmonis dalam kehidupan bersama.

Adaptasi tidak hanya dibataskan pada pengertian penyesuaian diri, namun secara luas adaptasi diartikan bagaimana seseorang berusaha untuk tetap bertahan hidup dengan kondisi tertentu, yang pastinya membutuhkan cara bagaimana seseorang tersebut bisa beradaptasi, dan mengapa harus beradaptasi. Untuk itu penulis mengutip teori dari seorang tokoh yaitu:

Menurut Usman Pelly (2013) "strategisatrategi adaptasi adalah cara-cara yang dipakai perantau untuk mengatasi rintangan-rintangan yang mereka hadapi dan untuk memperoleh suatu suatu kesinambungan positif dengan kondisikondisi latar belakng perantauan".

Adanya transmigrasi yang telah dijelaskan sebelumnya, maka Desa Batang Pane ini dihuni oleh berbagai suku/etnis yaitu diantaranya suku Sunda, Jawa, dan Angkola. Suku Sunda merupakan pendatang dari Jawa Barat, suku Jawa pendatang dari Jawa Tengah, dan Batak Angkola dari masyarakat Translok (transmigrasi lokal) sebagai suku asli atau disebut tuan rumah yang berada di Kecamatan Padang Bolak.

Hal itulah yang membuat Desa ini menjadi Desa multietnis, karena terdiri dari banyak suku/etnis. Namun dengan adanya beberapa suku/etnik yang ada di Desa Batang Pane II menjadikan Desa tersebut terlihat indah dengan keanekaragaman karena sesungguhnya perbedaan - perbedaan suku bangsa, perbedaan agama, adat dan kedaerahan yang seringkali disebut sebagai ciri masyarakat Indonesia yang majemuk. Interaksi dan komunikasi yang dijalani oleh suku Jawa, Sunda dan juga Angkola berjalan dengan lancar setelah melewati tahap-tahap yang mungkin menjadi penghambat untuk melakukannya karena memang 
tidak mudah apalagi dengan perbedaan bahasa yang menjadi kendalanya.

\section{Solidaritas Sosial}

Menurut Emile Durkheim dalam Susan (2010) solidaritas sosial adalah "kesetiakawanan yang menunjuk pada satu keadaan hubungan antara individu atau kelompok yang didasarkan pada perasaan moral dan kepercayaan yang dianut bersama yang diperkuat oleh pengalaman emosional bersama".

Masyarakat di Desa Batang Pane II memiliki rasa kesetiakawanan dan solidaritas yang tinggi. Meski Desa ini dihuni oleh bermacam etnis yang datang dari berbagai tempat, namun mereka bisa bergaul dengan etnis lainnya. Tidak ada yang merasa bahwa solidaritas hanya dibangun untuk etnis yang sama, namun mereka menganggap solidaritas dibangun untuk kehidupan bersama tanpa memandang perbedaan.

Selain solidaritas antara sesama pendatang yaitu etnis Sunda dan jawa, penulis juga melihat adanya solidaritas antara pendatang dengan etnis Angkola sebagai penduduk asli di Desa tersebut. Tidak tampak ada perbedaan antara mereka, semua dianggap sebagai keluarga yang sama-sama menempati wilayah yang sama.

\section{Faktor Hambatan}

Masyarakat rata-rata mengalami hambatan dalam berproses, seperti hambatan karena permasalahan tanah yang tandus, gangguan dari masyarakat setempat, kesulitan dalam berkomunikasi, dan adanya rasa takut. Hambatanhambatan ini lah yang harus mampu dihadapi masyarakat transmigran agar mereka mampuh bertahan hidup, dan hasilnya menunjukan bahwa mereka mampu.

\section{SIMPULAN}

Masyarakat transmigran yang ada di Desa Batang Pane II adalah masyarakat dari pulau Jawa yang datang ke Sumatera Utara dibawah program transmigrasi pada masa pemerintahan Soeharto tahun 1982. Jenis transmigrasi yang diikuti adalah transmigrasi umum, yaitu Transmigrasi program transmigrasi yang disponsori dan dibiayai secara keseluruhan oleh pihak pemerintah melalui depnakertrans (departemen tenaga kerja dan transmigrasi). Alasan utama masyarakat transmigran melakukan transmigrasi yaitu karena ingin mengubah hidupnya, meningkatkan perekonomian dan keinginan untuk hidup sejahtera dibandingkan dengan kehidupan didaerah asalnya. Masyarakat di daerah asal ratarata hanya bergelut di sektor pertanian dengan menggarap padi di persawahan milik orang lain dan hanya sebagai pekerja. Faktor tersebut yang mendorong mereka untuk memulai kehidupan di lingkungan yang baru dan rela meninggalkan tempat kelahiran demi sebuah tujuan hidup.

Adaptasi masyarakat transmigran terhadap penduduk asli berjalan dengan baik meskipun ada sedikit hambatan-hambatan yang dihadapi dalam menjalani prosesnya. Namun adaptasinya dapat dikatakan berhasil karena masyarakat transmigran yang predikatnya sebagai pendatang mampuh menjalin hubungan baik dengan penduduk asli sehingga tidak pernah terjadi konflik antar etnis disana. Masyarakat transmigran suku Jawa dan Sunda melakukan hubungan solidaritas yang baik terhadap penduduk asli, begitu juga sebaliknya. Kedekatan antar mereka menunjukan bahwa perbedaan status sebagai pendatang dan penduduk asli tidak menjadi suatu penghambat bagi mereka untuk melakukan solidaritas antar suku. Solidaritas antar suku tersebut sangat terlihat jelas pada saat mereka melakukan kegiatan seperti kerja bakti dalam pembangunan tempat ibadah, kerjabakti dalam perbaikan jalan, dan juga gotong royong dalam pesta hajatan ataupun kemalangan.

Masyarakat transmigran suku Jawa dan Sunda pada awalnya mengalami hambatanhambatan dalam beradaptasi di Desa Batang Pane II. Hambatan tersebut pertama karena tanah di Desa tersebut tandus sehingga masyarakat mengalami kesulitan untuk bercocok tanam. Tanah yang tandus tersebut tidak bisa dijadikan lahan pertanian, semua tanaman yang ditanam tidak bisa bertahan lama. Hambatan selanjutnya yaitu permasalahan pada komunikasi karena pada saat itu masing-masing suku yang ada (Jawa, Sunda, Batak) masih kental dengan bahasa daerahnya sehingga tidak saling memahami bahasa satu sama lain dan menjadi penghambat dalam berkomunikasi. Namunn seiring berjalnnya waktu masing-masing suku saling belajar bahasa suku lain sehingga saat ini mereka bisa memahami bahasa suku lain walaupun belum sepenuhnya. 


\section{DAFTAR PUSTAKA}

Arikunto, S. (2010). Prosedur Penelitian (Suatu Pendakatan Praktik). Jakarta: Rineka Cipta.

Budiarjo, M. (2008). Dasar-Dasar Ilmu Politik. Jakarta : PT Gramedia Pustaka Utama.

Bungin, B. (2008). Sosiologi Komunikasi: Teori, Paradigma, dan Diskursus Teknologi Komunikasi di Masyarakat. Jakarta: Kencana

Doyle, P.J. (1986). Teori Sosiologi Klasik dan Modren. Jakarta: PT Gramedia

Koentjaraningrat. (2009). Pengantar Ilmu Antropologi. Jakarta: Rineka Cipta

Mardalis. (2010). Metode Penelitian (Suatu Pendekatan Proposal). Jakarta: PT. Bumi Aksara.

Mulyadi. (2006). Ekonomi Sumberdaya Manusia Dalam Perspektif Pembangunan. Jakarta: PT Raja Grafindo Persada

Pelly, U. (2013). Urbanisasi dan Adaptasi, Peranan Misi Budaya Minang Kabau dan Mandailing. Medan: Unimed Press

Soekanto, S. (2000). Beberapa Teori Sosiologi tentang Struktur Masyarakat. Jakarta: CV Rajawali
Soekanto, S. (2006). Sosiologi Suatu Pengantar. Jakarta: PT Raja Grafindo Persada

Subagyo. (2012). "Pengambangan Nilai dan Tradisi Gotong Royong dalam Bingkai Konservasi Nilai Budaya", Indonesian Journal of Conservation Vol. 1 No. 1 Juni 2012.

Sugiyono. (2009). Metode Penelitian Pendidikan. Bandung: ALFABETA.

Sugiyono. (2012). Metode Penelitian Pendidikan Pendekatan Kuantitatif, Kualitatif, dan R\&D. Bandung: ALFABETA

Suparno, E. (2007). Paradigma Baru Transmigrasi Menuju Kemakmuran Rakyat. Jakarta: Departemen Tenaga Kerja dan Transmigrasi Republik Indonesia

Susan, N. (2010). Pengantar Sosiologi Konflik dan Isu-isu Konflik Kontemporer. Jakarta: Kencana

Winarto \& Herimanto. (2008). Ilmu Sosial \& Budaya Dasar. Jakarta: Bumi Aksara 